\title{
Análisis del portal educativo PerúEduca desde un enfoque multimodal
}

\section{Carmen Maribel Carpio Medina}

Universidad de Costa Rica

maribelaqp1@gmail.com

Recibido: 18/09/2020

Aprobado: 02/12/2020 


\section{Resumen}

Los portales educativos son espacios de acceso a internet, planificados mayormente para un ámbito formal escolarizado. En ellos, los usuarios obtienen servicios y productos digitales legitimados por la institución que los gestiona. Por ello, en cierta forma, los portales son la cara pública de tal institución. Este artículo investiga el portal PerúEduca con el propósito de analizar dos espacios específicos: el interfaz de Inicio y el interfaz del repositorio de materiales educativos. En tanto PerúEduca es una plataforma de gran alcance, se convierte en una herramienta de aprendizaje muy potente que da forma a experiencias de educación a distancia a miles de usuarios. En este sentido, es necesario optimizar su utilización. El análisis se realizó acorde con el marco multimodal para analizar sitios web propuesto por Pauwels (2012). Los resultados mostraron que PerúEduca se percibe más como un proveedor de noticias, que como una plataforma interactiva. El portal no muestra principios de accesibilidad y algunas funciones dependen del registro. En el repositorio, los usuarios acceden al saber producido por otros sin generar contribuciones. Una tercera parte de recursos son reproducciones digitales de libros impresos, y cerca de la mitad de ellos no son fácilmente utilizables, puesto que no responden al botón de búsqueda. También, se evidenció que la mayoría de los recursos corresponden al nivel Secundaria, al área de Ciencia y Tecnología, y que existen muy pocos de autoría nacional. Los hallazgos muestran que es necesario descentralizar la generación de conocimiento y promover la participación activa de los usuarios. terfaz

Palabras clave: Portales educativos, multimodal, diseño web, repositorio, in-

\section{Analysis of the educational portal PerúEduca, from a multimodal framework}

\section{Abstract}

Educational portals are places of access to the Internet, mainly planned for a formal educational community. In them, users access digital services and products validated by the institution that manages them. Thus, in a way, the portals become the public representation of such an institution. This article investigates the PerúEduca portal, with the purpose of analyzing two specific section, the Home page interface and the repository of educational resources. As PerúEduca is a powerful platform, it becomes a very powerful learning tool that shapes distance education experiences for thousands of users. Thus, it is necessary to optimize its use. The analysis was carried out according to the multimodal framework for analyzing websites proposed by Pauwels (2012). The results showed that PerúEduca is perceived more as a news provider than as an interactive educational platform. The portal does not show accessibility principles and some functions depend on login. In the repository, users access the knowledge produced by others, without generating contributions. One third of the resources are digital reproductions of printed books and about half are not easily usable since they are not indexed to the search button. It was also evidenced that the majority of resources belong to the secondary level, to the area of science and technology, and that there are few of national authorship. The results show that it is necessary to decentralize the generation of knowledge and promote the active participation of users.

Key words: Educational portals, multimodal, Web design, repository, interface 


\section{Introducción}

Desde el año 2001, el Ministerio de Educación del Perú (Minedu) ofrece el portal educativo "PerúEduca. Sistema Digital para el Aprendizaje" (en adelante, PerúEduca) como instancia oficial y gratuita de alcance nacional (PerúEduca, 2016). Entre sus principales finalidades, se encuentra brindar acceso a contenido educativo temático aprobado desde la normativa educativa, facilitar herramientas para generar nuevos contenidos, y promover redes de participación e intercambio entre los actores educativos (Flores y Vásquez, 2013). Dado que su despliegue ocurre en el ámbito digital, PerúEduca es parte de las Tecnologías de la Información y la Comunicación (TIC).

$\mathrm{Al}$ enfrentar cualquier forma de tecnología, por ejemplo, al utilizar una computadora, "entramos a formar parte de una red social de empeños e ideologías que nos construyen en tanto usuarios. De esta forma aceptamos reglas, límites y adoptamos actitudes..." (Scolari, 2008, p.261). Acorde con esta idea, no solo resulta crucial analizar los efectos de la tecnología sobre los usuarios, sino también la tecnología en sí misma y en diálogo con los mismos.

\section{Características de los portales}

En el año 2004, PerúEduca se integró a la Red Latinoamericana de Portales Educativos (Relpe). Esta red se mantuvo en funcionamiento hasta el año 2016 y se encargó de reunir los portales nacionales de aproximadamente 24 países. De acuerdo con Relpe (2013), los portales educativos deben mantenerse como espacios públicos y abiertos a fin de garantizar la oferta de la equidad educativa. Además, debido al alcance masivo que se espera de ellos, su administración solo puede realizarse desde la gestión y/o el financiamiento estatal.

Un portal educativo debe brindar una experiencia que promueva el trabajo colaborativo, la creatividad, el pensamiento crítico y la interactividad tanto de los usuarios con el portal, como entre ellos. En concordancia con estas ideas, algunos criterios usados para valorar los portales educativos fueron presentados por Relpe (2013) en cuatro aspectos:

- Portales como comunidades de usuarios que se registran y permanecen en el sitio, lo utilizan, crean recursos y permiten el flujo de la información. No se prioriza la cantidad de visitas, sino la calidad del acceso. En ese sentido, el registro de visitas debe evaluarse en función del índice de permanencia.

- Portales como curadores; es decir, acreditan la revisión de contenidos, y garantizan la adecuación curricular y la calidad académica.

- Portales como plataformas de trabajo, que incluyen herramientas para la producción de contenidos. Para ello, se debe anticipar el riesgo latente de subir al portal información que no ha sido revisada y que podría contener errores.

- Portales en relación con ministerios e inclusive con el ámbito privado. 


\section{Datos estadísticos sobre el uso de internet y del portal PerúEduca}

El Instituto Nacional de Estadística (Bonett et al., 2020) reportó que 81,2 \% de la población peruana hace uso diario de internet. Sin embargo, a nivel nacional, solo $35,6 \%$ de los hogares cuentan con computadora, mientras que $40,1 \%$, con servicio de internet. Se ha encontrado que la población accede a internet de las siguientes formas: $53,4 \%$ solo a través del teléfono celular; $19,0 \%$ accede en el hogar y teléfono celular; $2,5 \%$ accede solo a través de una cabina pública; y $0,2 \%$, solo en un establecimiento educativo. En relación con la última cifra, es oportuno señalar que, en el año 2018, solo 0,5 \% declaró haber accedido a internet en un establecimiento educativo (Costa et al., 2018).

Estos hallazgos ponen de manifiesto que la conectividad sigue siendo un aspecto pendiente para más de $50 \%$ de la población peruana y que, en este sentido, las instituciones educativas no han constituido un apoyo para el cierre de la brecha de acceso digital. Por otro lado, también se hace evidente la necesidad de incorporar principios de adaptación a los recursos educativos digitales y en el software, que permitan, por ejemplo, su utilización en teléfonos celulares.

Para efectos de esta investigación, se solicitó estadística sobre el uso de PerúEduca a la jefatura de la Dirección Tecnológica en Educación. Los datos remitidos por dicha oficina fueron los siguientes: hasta julio del 2019, el promedio de visitas diarias a PerúEduca fue de 26255 . Por su parte, la cantidad de usuarios que se registraron en el portal, es decir, que se crearon un perfil, fue de 903 024. De ellos, 289838 eran estudiantes; 509 344, profesores; y 103 842, padres de familia (M. Mendoza, comunicación personal, 5 de julio de 2019). Cabe señalar que la población de directores de instituciones educativas fue incluida dentro de la categoría profesores.

Para poner en contexto la data previamente señalada, es oportuno indicar que la cantidad de estudiantes matriculados en Educación Básica Regular, Básica Alternativa y Básica Especial en el año 2019 fue de 8260 570, mientras que la cantidad de profesores registrados fue de 535555 (Unidad de Estadística Educativa del Ministerio de Educación del Perú [Escale], 2020). De la comparación de ambos grupos de cifras, se infiere que el alcance de usuarios del portal para el año 2019 fue de aproximadamente 3,51 \% a nivel de estudiantes, y $95,11 \%$ a nivel de profesores. Esto significa que la mayor parte de la población de profesores peruanos cuenta con acceso a la producción del portal. Asimismo, cabe aclarar que, hasta noviembre de 2020, la cantidad de visitas en la plataforma había llegado a las 33763410 (Portal PerúEduca, 2020). 


\section{Marco conceptual}

\section{La interactividad}

La interactividad es un término sobre el cual todavía se sigue discutiendo. Este no es exclusivo de los medios digitales, puesto que implica un proceso que también ocurre en ámbitos de comunicación interpersonal. De hecho, puede ser mediado tecnológicamente, por ejemplo, en la mensajería instantánea; en este caso, dos o más personas se comunican entre sí, e interactúan a través del medio digital.

Por otro lado, la interactividad también puede ser entendida como un producto. Este concepto incluye la interacción del usuario con la computadora, y la del usuario con los diversos textos que puede encontrar en la computadora (Adami, 2015). En este punto, de acuerdo con Calsamiglia y Tusón (2001), el lenguaje siempre es dialógico. Esto sucede así incluso en un monólogo o un mensaje digital de entrega asincrónica, pues el diálogo se concreta desde el mismo momento de la enunciación (Calsamiglia y Tusón, 2001). El enunciador genera un mensaje en función de la idea que tiene sobre su interlocutor. En este orden de ideas, el enunciador concretiza, a través del diseño de interacción que imprime en el mensaje emitido, la idea que tiene sobre las características de su interlocutor. Según Scolari (2008), la interactividad aparenta una forma de libertad para el usuario, pero, en realidad, este sentimiento de control y poder se encuentra limitado por el enunciador/creador del entorno interactivo, pues este ha definido previamente las posibilidades que el usuario podrá elegir. En concordancia, según Adami (2015), la interactividad define, en un sitio web, aquello que les está permitido hacer a los usuarios.

\section{La multimodalidad}

El cambio digital moderno traslada el discurso hacia la web. Con ello, se da lugar a cambios en los modos de representación del conocimiento, y surgen nuevas relaciones sociales múltiples, ubicuas e interconectadas. En este escenario, para Gladic-Miralles y Cautín-Epifani (2016), la multimodalidad consiste en el uso variado de diversos sistemas semióticos. Cada uno de ellos interactúa con los demás en la construcción de significado. Algunos de estos sistemas semióticos son los siguientes: el verbal (palabras, oraciones); el gráfico (fotos, ilustraciones, espacios blancos); el matemático (signos, fórmulas); y el tipográfico (color, tamaño) (Parodi, 2010). Así, el texto escrito deja de ser la forma de comunicación dominante y se da un giro hacia lo visual-digital. Sin embargo, a pesar de la gran cantidad de imágenes publicadas, "la esencia de internet no es visual en absoluto" (Bal, 2017, p.33). Más bien, las imágenes suelen estar rotuladas con información explicativa y pueden ir acompañadas con algún sonido; así, tienen lugar los recursos de tipo multimodal. 
La multimodalidad también se constituye como un enfoque potente de análisis de textos, formas de comunicación y practicas sociales. Este enfoque está centrado en analizar la convergencia de múltiples sistemas/modos semióticos en los procesos de representación y comunicación para la creación de significados (Kress, 2010). Ahora bien, el significado es dialógico, se construye y no ocurre con anticipación a ser interpretado. Es el resultado del diálogo entre el observador y el objeto. Este diálogo siempre está inmerso en luchas de poder que van a reflejar las imposiciones de la episteme dominante.

Un supuesto en la investigación de análisis multimodal es que la creación de significado se organiza por medio de la selección; la interacción; y el ensamblaje de diferentes sistemas semióticos, por ejemplo, las posibles combinaciones de diseño, imagen, color y texto escrito, basados en las motivaciones y los contextos sociales de los potenciales intérpretes (usuarios). Esto no ocurre de forma aislada, sino en interrelación con las normas vigentes del contexto social $y$ en el interés del creador del significado (autor) por generar una respuesta en el intérprete (Michelson y Álvarez, 2016).

Por lo explicado, en el presente trabajo, PerúEduca y sus recursos educativos se consideran espacio y textos multimodales, respectivamente, puesto que contienen diversos sistemas semióticos. Sin embargo, en esta investigación, se utiliza, sobre todo, la multimodalidad como una herramienta de análisis del portal web.

Los sitios web se constituyen como lugares donde se crean, movilizan y compiten diversos discursos. El discurso comprende una simultaneidad de formas. Según Kress y Van Leeuwen (2001), todo discurso es multimodal. De hecho, Keller señala que "la noción del discurso resulta muy adecuada para analizar procesos, prácticas y políticas sociales del conocimiento en las sociedades modernas. Ayuda a proporcionar un entendimiento teórico más sutil de la idea de 'stock del conocimiento.' (2010, p.9).

De acuerdo con estos planteamientos, las instituciones, a través de sus sitios web (entre ellos, los portales), configuran, publican y distribuyen discursos en forma de conocimiento social en un espacio y tiempo ubicados. En esta difusión del conocimiento válido, se crean las condiciones que dan forma a los sujetos y a las sociedades. Por tal motivo, es necesario someterlos a un análisis crítico.

\section{El diseño de sitios web}

Según Martínez Rolán (2019), "el diseño web es una actividad ligada a la creación de sitios web para su consumo interactivo por medio de un navegador" (p.29). En esta actividad, la interfaz puede ser entendida como el "formato de comunicación entre el humano y la máquina" (Area, 2017, p.19). Acorde con esta idea, el diseñador quedaría invisibilizado. Según Scolari (2004, p.84), este ocultamiento viene a ser una consecuencia indirecta del mito de la interfaz transparente. En oposición a esta idea mítica, las interfaces no son en absoluto 
agentes neutrales, "no son dóciles instrumentos en las manos de los usuarios, sino complejos dispositivos cognitivos y semióticos donde se negocia el significado de las interacciones" (Scolari, 2008, p.244).

Vista así, la interfaz es un lugar que comunica directamente al usuario con el mensaje plasmado por el diseñador a través de un sistema informático. Además, no se trata de un espacio estático, sino de un lugar de interacción, donde el usuario puede reconocer y acceder a diversas funciones, independientemente de la tecnología que se encuentra detrás del sitio web, como la programación o el código fuente (Rovira y Marcos, 2013).

La interacción humano-computadora no siempre ha sido la misma. El cambio tecnológico, desde el monitor con pantalla monocromática hasta la moderna pantalla multitáctil ${ }^{1}$, ha dado lugar a la sofisticación del diseño web a través de la implementación de nuevas y diversas disciplinas. Un esquema organizador de este conjunto de disciplinas, alrededor del diseño web, fue planteado por Olsen (2003), el cual se puede apreciar en la figura 1.

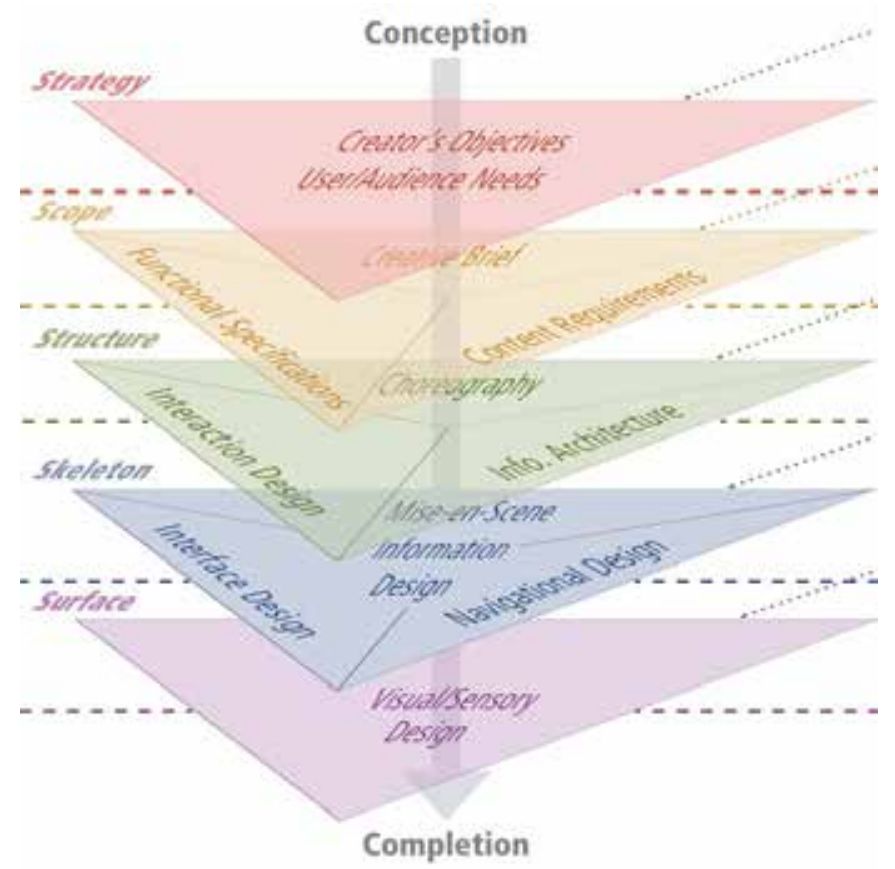

Figura 1. Modelo de diseño web (Olsen, 2003)

Nota. Tomado de http://boxesandarrows.com/files/banda/expanding_the_approaches_to_user_experience/uxapproachesmodel.pdf

1. Consiste en una pantalla táctil o panel táctil que reconoce simultáneamente múltiples puntos de contacto, así como el software asociado a esta, que permite interpretar dichas interacciones simultáneas. 
Este modelo muestra un orden cronológico para el desarrollo de un sitio web. Se extiende desde la concepción o idea inicial, hasta la realización final. Todo el proceso se organiza en cinco fases: (a) la estrategia, que identifica los objetivos del sitio web; (b) el alcance, que identifica las necesidades del usuario; (c) la estructura, que indica las funciones y requerimientos del sitio web; (d) el esqueleto, que diseña los sistemas de navegación, organización, etiquetado y búsqueda; y (e) la interfaz, que presenta el sitio web. Así también, en la figura 1 , se observan las disciplinas que participan en las distintas fases. Algunas de ellas son el diseño visual de interacción, el de navegación, el de interfaz, o la arquitectura de la información.

En el modelo planteado por Olsen (2003), los límites son claros; sin embargo, en la realidad, es difícil determinar dónde empieza una disciplina y dónde termina otra, pues, en varias ocasiones, se superponen entre sí. Para atender a esta poca limitación, Rovira y Marcos (2013) sistematizaron las disciplinas participantes del diseño web en cinco categorías:

- Arquitectura de la información. Consiste en "estructurar, organizar y etiquetar" información para facilitar que los usuarios puedan encontrarla (Pérez-Montoro, 2010, p.24). En el cumplimiento de estas actividades, se utilizan sistemas de búsqueda y lenguajes documentales que sirven para indexar ${ }^{2}$ y clasificar la información.

- Usabilidad. Según Scolari (2008), la usabilidad "se reduce a una especie de superación de barreras arquitectónicas: un sitio usable es aquel que facilita la navegación y permite llegar rápidamente a la información buscada" (p.256). La usabilidad de un producto desarrollado por la arquitectura de la información se evalúa por medio de pruebas. Estas evaluaciones sirven para hacer ajustes y mejoras. Algunos principios de usabilidad también son proporcionar una experiencia satisfactoria, y ser fácil de aprender y de recordar (Rovira y Marcos, 2013).

- Accesibilidad. Comparte el mismo objetivo que la usabilidad: que la mayor cantidad de usuarios pueda hacer el mejor uso del sitio web (Caballero-Cortés et al., 2009). Un aspecto específico de la accesibilidad es que intenta vencer ciertos problemas sensoriales del usuario para acceder a la información, por ejemplo, el problema de baja visión. "La accesibilidad sería entonces la capacidad de una página web, o una aplicación, para facilitarle a los usuarios (independientemente de sus niveles de discapacidad física o tecnológica) el acceso a la misma y a sus contenidos" (Serrano, 2009 , p. 67). Estos son algunos criterios de accesibilidad propuestos por Serrano (2009): proporcionar textos alternativos para todo elemento que no sea escrito; mostrar correctamente el contenido del sitio web sin cargar la hoja de estilos (CSS), scripts (JavaScript), applets, animaciones flash, u

2. Ordenar datos o información de acuerdo con un criterio común a todos ellos, para facilitar su búsqueda 
otros; informar la estructura general del sitio web para ubicar siempre al usuario; evitar recursos gráficos móviles que dificulten la navegación, por ejemplo, los parpadeos en la pantalla o gifs en movimiento.

- Diseño de interacción. Es la forma como el usuario se relaciona con el sitio web a través de la interfaz. En el diseño de interacción, se pueden encontrar los siguientes elementos (Martínez Rolan, 2019, p.36):

- La navegación y las rutas de acceso. Conducen hacia la información. Deberían tener un máximo de cuatro niveles de profundidad, evitar los callejones sin salida e integrar distintas vías de acceso al contenido del sitio web.

- Los eventos. Son las acciones que ocurren entre el usuario y el contenido de cada interfaz. La distribución de eventos toma en cuenta cómo se dispone la información en la pantalla, el movimiento de las imágenes, entre otros. - Los controles de interacción. Son los menús, botones y enlaces que permiten la navegación en el sitio. Algunos pueden ser contextuales, es decir, en forma de un listado de títulos/subtítulos a los que el usuario debe acceder para profundizar en algún tema. Con ello, se reduce el uso del scroll.

- Diseño de navegación. Es la forma como se organiza la información en el sitio web. Para visualizar la navegación, se utiliza por lo general el mapa del sitio ${ }^{3}$. Algunas formas de organización pueden ser linear, jerárquica, matriz, de malla completa, de red arbitraria o la combinación de ellas (Martínez Rolan, 2019, p.33), como se puede ver en la figura 2.
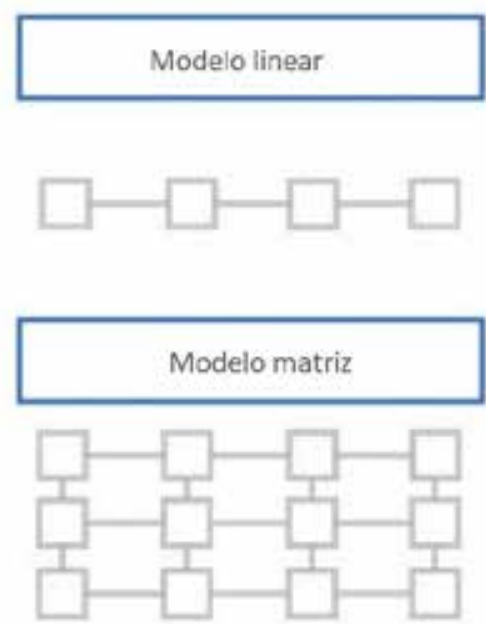
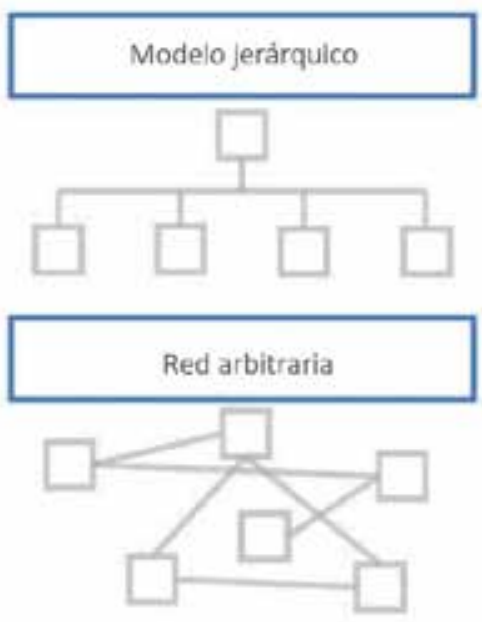

Figura 2. Formas de diseño de navegación

Nota. Tomado de Martínez Rolan (2019, p.34).

3. Es una representación gráfica sencilla, que muestra la distribución general de la información, las secciones e, incluso, puede contener las posibilidades de navegación entre ellas. 
- Diseño de interfaz. Las secciones habituales en la interfaz de un sitio web son el encabezado, el logotipo, los menús de navegación, el contenido principal, las migas de pan ${ }^{4}$, el banner de imágenes deslizables, el pie de página, y las ventanas emergentes intrusivas tipo рор up. En la figura 3, puede observarse un esquema del diseño de interfaz que corresponde a la página inicial de PerúEduca.

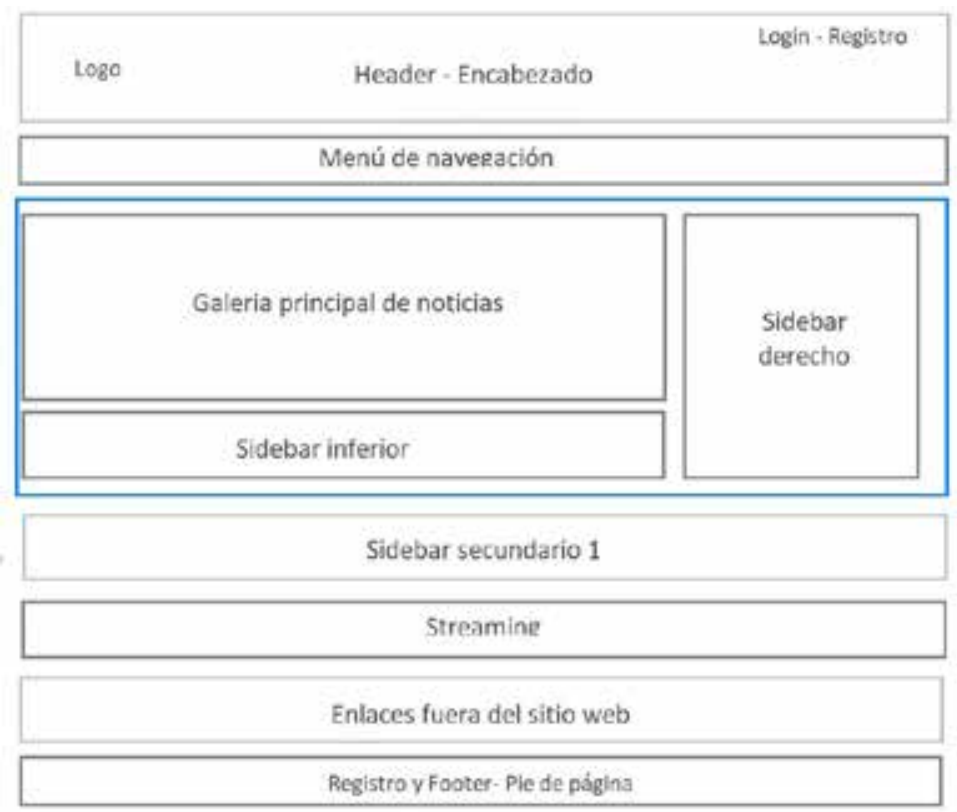

Figura 3. Formas de diseño de navegación en la página inicial de PerúEduca Nota. Elaboración propia, con base en PerúEduca (2020).

\section{Alfabetización visual}

La imagen no es una portadora autónoma de significado. En lugar de ello, los observadores deben aprender cómo interpretar su representación y cómo expresarse visualmente. De acuerdo con Villa (2008), para realizar la lectura literal de una imagen, es necesario abordar dos aspectos: el denotativo, es decir, lo descrito, y el connotativo, que viene a ser lo inferencial. En el denotativo, se incluyen aspectos morfológicos (punto, línea, color, textura y plano); dinámicos (movimiento, ritmo y tensión); y escalares (dimensión, escala y proporción). En el connotativo, se incluyen los referentes socioculturales (fecha, autor,

4. Es un descriptor de navegación que le indica al usuario su profundidad en el sitio web; también permite retroceder niveles. 
propósito, estilo de representación). Sin embargo, es necesario puntualizar que el análisis de la imagen ocurre de forma simultánea e interactuante. Así, el significado denotativo y el connotativo se afectan, y se integran armónicamente para revelar el significado global.

Hasta aquí, queda claro que la alfabetización visual implica la interpretación y la generación de imágenes. Al respecto, López-León (2017) señala que también interviene activamente en el desarrollo de otras competencias, tales como el pensamiento crítico y la solución de problemas.

\section{Metodología}

Los datos fueron recogidos del portal PerúEduca en su entorno usual de presentación: online. Los sitios web, por lo general, deben ser actualizados con cierta periodicidad, de allí que, para efectos del análisis, fuera necesario establecer un punto de corte. En este caso, el punto de corte del análisis se determinó hasta mediados de septiembre del año 2020.

La metodología de análisis se realizó bajo los aportes conceptuales del marco multimodal para analizar sitios web propuesto por Pauwels $(2012)^{5}$. Se analizaron dos espacios en el portal: la interfaz de Inicio (se accede desde el botón Inicio), y del repositorio (se accede desde el botón "materiales educativos"). En el primero, se revisaron las características de navegación, interacción, accesibilidad, perfiles y narrativa, mientras que, en el segundo, se analizó la distribución del contenido del repositorio, según modalidad, área curricular y autoría de los recursos educativos.

\section{Análisis de la página de Inicio del portal. Discusión de resultados}

\section{Datos de identificación}

- Título: PerúEduca. Sistema Digital para el Aprendizaje

- Institución: Ministerio de Educación del Perú (Minedu)

- Dirección web: http://www.perueduca.pe/

- Idioma de navegación: solo castellano

- Idioma de los materiales educativos: castellano o lenguas originarias

- Tipo de portal: web institucional de servicios y recursos educativos

- Tipo de acceso: parcialmente restringido y gratuito

- Perfiles: estudiante, profesor, familia, funcionario, periodista y aliado de empresa privada

- Tecnología: plataforma de gestión de contenidos (CMS) y de aprendizaje (LMS). Este soporte permite que, además de contar con un repositorio, también se puedan gestionar cursos $\mathrm{u}$ otras herramientas con mayor interactividad, como foros, blogs y wikis. 


\section{Inventario de características y temas destacados}

PerúEduca es un entorno virtual de acceso parcialmente restringido. En efecto, la navegación y la obtención de un perfil están permitidas solo para ciudadanos peruanos que cuenten con el documento nacional de identidad (DNI). El registro del usuario requiere la digitación del número de DNI y el código de ubicación geográfica que se encuentra en este documento. Al respecto, cabe remarcar la utilidad de contar con información precisa sobre los usuarios del portal, por ejemplo, cuál es su grupo etario, de qué regiones acceden y qué utilizan. Asimismo, según Cobo (2016), una arquitectura social de colaboración que promueva el aprendizaje y la generación de conocimiento en los espacios digitales requiere el cumplimiento de características tales como el reconocimiento entre pares, la confianza como valor agregado, y una estructura adaptable y flexible. En este sentido, el portal verifica la identidad de los usuarios a través del registro; ello puede generar cierta confianza en la red de usuarios. Sin embargo, aunque el portal dispone de herramientas de interacción, su uso no es promovido entre los usuarios.

De otro lado, también es necesario recordar que, en Perú, no todas las personas cuentan con DNI, sobre todo aquellas que residen en las zonas de más difícil acceso. Además, como se señaló antes, a nivel nacional, 53,4 \% de la población accede a internet solo a través del teléfono celular, mientras que $2,5 \%$, solo en cabinas públicas. Esto significa que los usuarios deben invertir minutos/dinero en los procedimientos de login (registro).

Durante el registro, el usuario debe elegir un perfil, ya sea como director, docente, estudiante, funcionario, periodista o aliado. Este perfil va a determinar el tipo de herramientas a las cuales tendrá acceso, por ejemplo, aula virtual, $b \log$, foro, wiki, la formación y participación en comunidades virtuales. En la figura 4, a continuación, se observa la navegación, principalmente lineal, en la interfaz inicial de PerúEduca:

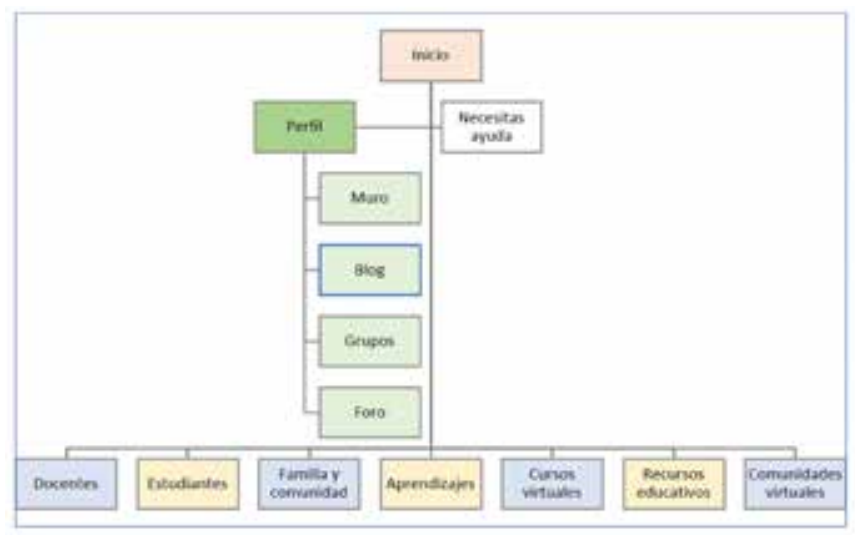

Figura 4. Navegación de la interfaz inicial en PerúEduca

Nota. Elaborado por la Dirección de Tecnologías (DITE) (M.

Mendoza, comunicación personal, 5 de julio de 2019). 
Se puede inferir que el estricto mecanismo de registro les comunica a los usuarios un sentido de comunidad, otorgado exclusivamente por ser de nacionalidad peruana. Ante esta situación, es válido preguntar lo siguiente: ¿cuál será la subjetividad que se crea en los niños migrantes, que radican actualmente en el país, cuando ellos intentan registrarse en el portal?

Así también, otros mecanismos principales para afirmar la identidad nacional se encuentran en los elementos visuales del sitio. El logotipo del portal es el mapa del Perú, y los colores predominantes en los botones del menú principal de navegación son el rojo y blanco, los colores de la bandera nacional.

Por otro lado, ciertas ausencias evidentes en la interfaz de Inicio son el mapa del sitio, que debería mostrar la navegación y estructura lógica de la organización, y la sección "Nosotros", que resultaría útil para presentar y explicar el propósito del portal. En contraposición, se puede observar una preeminencia de íconos que refieren a redes sociales para compartir la información, así como la oferta de cursos virtuales o eventos sobre tecnología, como se ilustra en la figura 5.

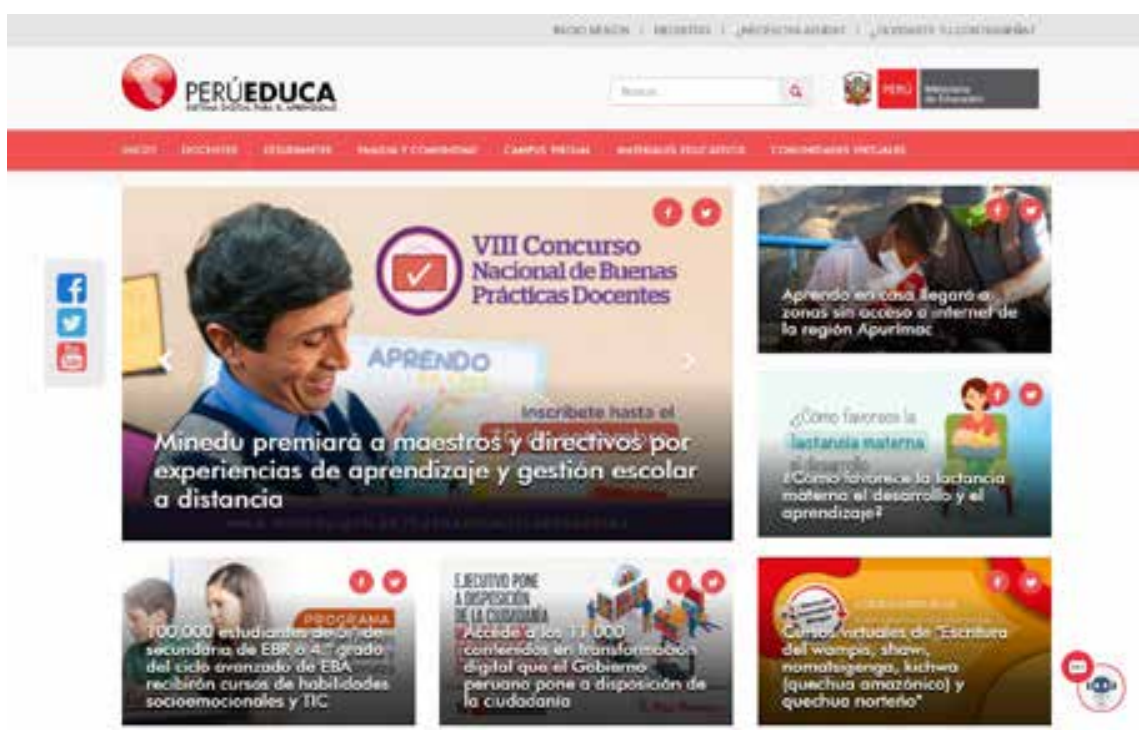

Figura 5. Captura de pantalla de la página de inicio de PerúEduca

Nota. Tomado de PerúEduca (2020). 


\section{Análisis de las características estilísticas lingüísticas y visuales}

Para determinar las características estilísticas del lenguaje, se analizaron quince títulos de noticias, presentes al momento del análisis en la galería y el sidebar de la interfaz de inicio ${ }^{6}$. De ellos, se identificó que siete corresponden a la modalidad oracional asertiva; seis, a la del modo imperativo; y dos, a la interrogativa. Así también, seis títulos están redactados en segunda persona; seis, en tercera persona; y tres, en primera persona. Por lo anterior, los modos más frecuentes para dirigirse al usuario son el asertivo y el imperativo; también, predomina el uso de la segunda persona en singular a través de palabras como "participa", "conoce" o "accede". Estas formas de comunicación facilitan la transmisión de cierta proximidad con el usuario.

Un hecho resaltante es que los mensajes del portal están prioritariamente dirigidos a docentes. De quince noticias presentadas, once de ellas están dirigidas a ellos; tres, a padres de familia; y una, a estudiantes.

En lo referido a las representaciones visuales, en el portal, no se utilizan íconos representativos, excepto una lupa de búsqueda. El color de fondo es claro y facilita la navegación. Los tipos de fuente usados son Arial y Century, los cuales no contienen serifas ${ }^{7}$. En general, este tipo de fuente permite que los textos sean legibles y no causen fatiga al usuario. Sin embargo, se utilizan letras blancas, lo que podría dificultar la lectura a personas con baja visión, y no es posible hacer ajustes en los contrastes. Por ello, las personas con necesidades especiales sensoriales pueden presentar dificultades para el acceso. Este hecho resulta contradictorio con el discurso de inclusión, que se promueve desde las publicaciones del mismo portal educativo.

En la barra de navegación principal, los títulos muestran un tamaño de fuente menor, en relación con el resto de la interfaz. Este hecho asigna simbólicamente más importancia a la lectura de las noticias sobre las otras secciones del portal. Las noticias tienen título y enlace al texto completo; son presentadas en la galería en formato de cinco cajas rectangulares ubicadas en el sidebar (Figura 5). Los títulos están remarcados en letras negritas y tienen efecto sombreado. Esto ocasiona que compitan con el contenido lingüístico interno de la noticia, pues, en once títulos, de los quince analizados, las palabras se superponen. Lo anterior genera una interfaz llena de elementos destacados que hace difícil mantener la atención en un solo aspecto.

En el uso del recurso visual, se evidencia la preponderancia del texto escrito sobre el gráfico. En 11 casos, la imagen está compuesta por elementos gráficos y palabras a modo de afiche. En tres casos, la imagen solo contiene palabras, y en un caso, la imagen solo contiene elemento gráfico. Así también, en 10 casos, el título de la noticia se coloca encima de las imágenes, lo que dificulta

6. Para mayor detalle, consultar Anexo 2 y Anexo 3

7. Son remates o adornos ubicados generalmente en los extremos de las líneas de los caracteres tipográficos, por ejemplo, en el tipo de fuente Time New Roman. 
su visualización. Por su parte, en 11 casos, las imágenes contienen palabras que repiten la misma información del título de la noticia, lo cual subordina el texto gráfico al texto escrito.

Sobre los personajes presentados en las noticias, se encontró que 18 gráficos correspondían a hombres y 14 , a mujeres. Las noticias que solo tenían gráficos de hombres estaban referidas al fortalecimiento de la educación a distancia, la premiación a docentes, la participación en encuestas y el trabajo docente en ámbitos rurales, mientras que las que solo contenían gráficos de mujeres estaban referidas a la capacitación en ofimática, manejo de tablets, utilización del Regiep (registro de personas que han sido condenadas o procesadas por delitos), y lactancia materna. En siete noticias, se utilizaron fotografías. De ellas, tres correspondían a estudiantes y cuatro, a docentes. Ninguno de los personajes en las fotografías miraba hacia la cámara. Esto produce que el personaje pierda centralidad en la foto y que, en lugar de ello, cobre importancia aquello que el personaje observa. En cinco fotografías, los personajes observaban elementos tecnológicos. Por lo anterior, se concluye que el uso de algunas imágenes transmite roles de género y prioriza el objeto tecnológico. Un aspecto final para comentar es que en ningún caso se presentaban personas adultas mayores.

En cuanto a la maquetación y el diseño, en líneas generales, se puede afirmar que resulta sencillo entender la organización del portal. Básicamente, se trata de un espacio con noticias y un menú principal que permanece estable; por ello, brinda cierta seguridad para la navegación. En la galería, el banner móvil de noticias presenta una secuencia ordenada de anuncios, que cambia cada seis segundos. Este banner ocupa cerca de la mitad de la pantalla, lo cual obliga al usuario a utilizar el scroll para acceder al resto del sitio. Visto así, el sitio refiere con demasiada similitud a una pizarra de noticias.

Finalmente, no se encuentran recursos sonoros o videos en la página de inicio. Otro aspecto ausente en el espacio del registro, ubicado en el footer, es la diversidad cultural. Esta ausencia resulta especialmente sensible en un contexto multicultural como el peruano. El portal tampoco presenta enlaces hacia sitios externos, diferentes del Minedu, y no presenta certificación visible $\mathrm{u}$ opciones de accesibilidad.

\section{Narrativa principal y perfiles}

El portal se muestra como un espacio para el uso de diferentes perfiles de usuario. Sin embargo, de acuerdo con la revisión, el usuario principal es el docente, quien es continuamente invitado a recibir algún tipo de capacitación. Además, aunque el sitio contiene herramientas interactivas, estas no son puestas a disposición ni son promovidas. En lugar de ello, el docente es colocado en un rol receptivo.

Así, PerúEduca no se presenta como un espacio de construcción e intercambio entre usuarios, sino que se trata, más bien, de un sitio donde el Minedu comunica noticias e indicaciones a los docentes. Cabe señalar, también, que 
todas las noticias pueden ser comentadas por los usuarios que previamente se han registrado. Al respecto, a partir de una revisión rápida, se constató que ninguna publicación ha recibido un comentario negativo o una expresión de desacuerdo. Esto motiva a suponer que los comentarios son moderados antes de su publicación.

En cada perfil, se presentan noticias que, de acuerdo con PerúEduca, son adecuadas al interés del usuario. Por ejemplo, en el perfil "Estudiantes", la noticia trata la importancia de las horas de sueño; en el perfil "Familia", las alertas del bullying; en el perfil "Docentes", recomendaciones para una mejor relación entre el docente y los padres de familia. Los demás perfiles no tienen personalización de noticias y no están visibles en el menú. Previo registro, los perfiles de docentes y estudiantes cuentan con la posibilidad de crear un blog, una línea de discusión en el foro o un grupo, y una vez creado el grupo, se puede usar la wiki. Sin embargo, estas opciones dependen de la aprobación de un moderador.

\section{Análisis de la organización de la información y estrategias de priming}

En el sitio, se distinguen cinco secciones horizontales que siguen un patrón de navegación lineal:

- Encabezado. Contiene el inicio de sesión, botones de ayuda, el botón de búsqueda, y el logotipo o marca institucional. Es decir, permite la interactividad de identificación personal, institucional y búsqueda.

- Menú de navegación. Contiene el menú principal, que se mantiene en todas las pantallas y en todos los perfiles. Consta de los siguientes siete botones: Inicio, Docentes, Estudiantes, Familia y comunidad, Cursos virtuales, Recursos educativos, y Comunidades virtuales. Aquí, se encuentra la interactividad de navegación interna.

- Galería, sidebar derecho e inferior. Contiene la galería principal de noticias en un banner móvil deslizable, que muestra las noticias destacadas y el sidebar, con cinco cajas adicionales pequeñas con otras noticias. En este espacio, la interactividad conecta al usuario con un mensaje.

- Sidebar secundario, streaming. En este bloque, los botones direccionan hacia sitios externos de la plataforma, tales como el repositorio de streaming o educasitios. Aquí, se encuentra la interactividad de navegación externa al sitio, pero siempre dentro del ámbito administrado por el Minedu.

- Registro y footer. En este espacio, además del registro, se encuentra el botón "mapa", que dirige a Google Maps. Allí, se pueden ubicar las instituciones educativas conectadas a PerúEduca y se puede conocer con cuáles recursos tecnológicos cuentan. También, se encuentra el botón de soporte, que direcciona a un espacio con preguntas frecuentes, números de teléfono y un formulario de consulta. 
Es necesario notar que los botones de acceso a las redes sociales se ubican al lado izquierdo de la pantalla y están siempre en la misma ubicación independientemente del scroll (desplazamiento) que se realiza en la página de inicio. Así también, al lado derecho, se encuentra un asistente virtual de chat (Edubot), que tiene como función principal dirigir al formulario de consultas.

La estrategia más evidente de priming ${ }^{8}$ está en enfatizar la oferta de cursos y promover el uso de las redes sociales. En este último punto, desde PerúEduca, no se muestra algún tipo de orientación al usuario para conducirse en redes. Otro aspecto por comentar es la dificultad para comunicarse con "alguien" dentro del sitio. No se encuentran rostros visibles encargados de la administración. Ante cualquier duda, el usuario debe completar un formulario que puede ser respondido en un lapso máximo de treinta días.

En lo referido al menú principal y los submenús de navegación, se ha encontrado que, entre los siete botones que contiene el menú principal, los cuatro primeros corresponden a "Inicio" y los perfiles mencionados en la estructura general. Los siguientes tres botones son los siguientes:

- Campus virtual. Este botón dirige al usuario hacia opciones fuera de la plataforma. En este nuevo espacio, se presenta la oferta virtual de "Cursos en desarrollo", "Cursos en inscripción", "Para estudiantes EBA" y "Para estudiantes de Educación". Cada curso tiene indicado el nombre, la duración y la cantidad de módulos; asimismo, remarcado en fondo rojo, se indica si el curso cuenta con constancia o certificado. De esto, se puede inferir que la importancia de llevar el curso no solo radica en el hecho de aprender, sino también en acreditarlo. Para tal fin, la plataforma presenta la posibilidad de generar automáticamente y descargar las constancias de participación.

- Comunidades virtuales. A través de este botón, se puede acceder, previo registro, a seis comunidades presentadas y promovidas desde el Minedu. Al hacer clic en alguna de ellas, el usuario sale del entorno de PerúEduca.

- Materiales educativos. Este botón brinda acceso al repositorio de recursos y se despliega dentro de la misma plataforma. Los recursos se organizan por nivel, según sea Inicial, Primaria y Secundaria; luego, al interior de cada nivel, se organizan según las áreas curriculares formales del plan de estudios. Otra forma de organización es por tipo de recurso, según sean audios, fascículos, infografías, juegos, libros, módulos, objetos de aprendizaje $^{9}$, simuladores, sitios recomendados, software, y textos del MED o videos. Los módulos "Materiales Educativos BIAE 2020" y "Recursos educativos abiertos" se presentan independientes del menú de materiales educativos, a modo de repositorios dentro del repositorio (Figura 6).

8. El priming consiste en condicionar una conducta en el usuario al exponerlo a ciertos estímulos.

9. Es un conjunto de recursos digitales autocontenible, reutilizable y responde a un propósito educativo. Al menos, presenta contenido, actividades y evaluación. 


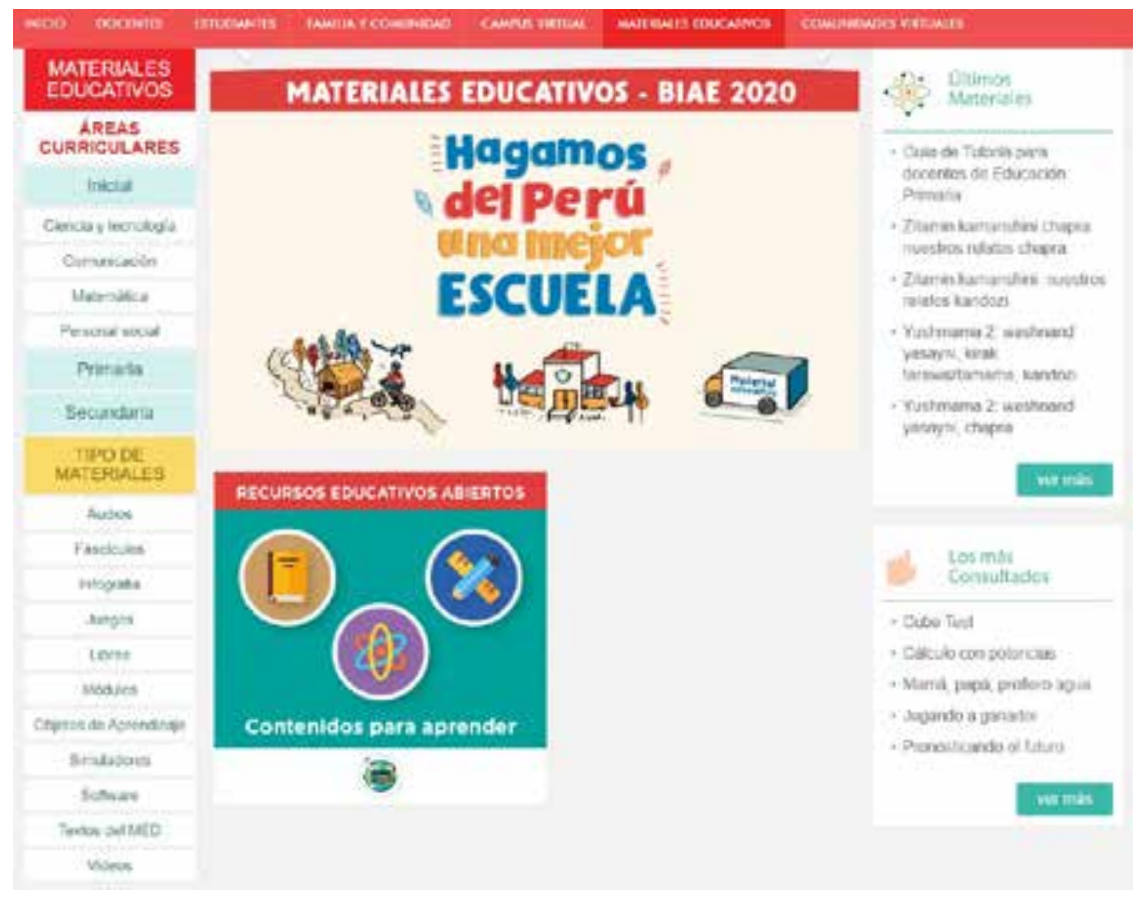

Figura 6. Captura de pantalla de la sección materiales educativos Nota. Tomado de PerúEduca (2020).

\section{Análisis del contexto tecnológico}

Algunas características de la tecnología empleada en el portal son estas:

- Es multiplataforma; se puede acceder desde diversos dispositivos como computadoras, laptop, teléfonos celulares o tabletas.

- No se evidencia alguna certificación de accesibilidad para el contenido.

- Soporta diversos navegadores: Chrome, Internet Explorer y Firefox.

- Servidor web: Apache 2.4.6.

- Sistema operativo: CentOs

- Sistema de gestión de contenidos: Liferay 6.1.0, Moodle y WordPress

De lo anterior, se infiere que, al menos desde el aspecto tecnológico, se opta por brindar acceso al usuario desde diversos navegadores web y en diferentes aparatos tecnológicos. Además, se prioriza el uso de recursos de software libre, gratuitos de código abierto como Moodle, Apache o Liferay. 


\section{Análisis de contenido en la sección "materiales educativos". Discusión de resultados}

En esta parte del análisis, se revisó la sección "materiales educativos" que corresponde al repositorio digita ${ }^{10}$. Un repositorio debe al menos realizar cinco funciones al servicio del usuario: (1) buscar información, (2) mostrar un resumen antes de ingresar al recurso, (3) evaluar la pertinencia del recurso, (4) permitir el uso/descarga del recurso, y (5) conectar a los usuarios (Yuan et al., 2015).

\section{Inventario de características y temas destacados}

En PerúEduca, el usuario no requiere registro para acceder al repositorio. La organización principal se ubica en el menú lateral izquierdo. En este menú, la navegación es sencilla, con una forma directa de presentación y filtros que facilitan su manejo. Los materiales educativos están organizados por niveles, áreas curriculares y tipo de recursos (Figura 7). La mayoría de los materiales responden al botón de búsqueda, que es accesible en todo momento de la navegación. $\mathrm{Al}$ respecto, cabe indicar que la usabilidad del botón de búsqueda distingue tildes. En consecuencia, es preciso escribir correctamente la consulta para que la búsqueda sea exitosa. Además, hacen falta etiquetas ${ }^{11}$ que describan, en cada recurso educativo, las competencias curriculares que están siendo abordadas, por ejemplo, resolución de problemas o indagación científica, entre otras.

\section{Análisis en profundidad del contenido del repositorio}

En el repositorio digital de PerúEduca, se encontraron 3102 recursos educativos (Figura 7). De ellos, 1033 están catalogados como Textos MED (textos de autoría del Minedu); estos representan un poco más de la tercera parte del total de los recursos (33,3\%). Para efectos del análisis, se excluyeron los Textos MED y también otros materiales catalogados como libros. Esto se debe a que se encuentran en formato PDF, un tipo de presentación más cercano a un material convencional impreso que a un recurso digital. Además, el gran peso cuantitativo que tienen, dada la cantidad existente, hubiera dificultado el análisis, pues incluirlos habría requerido agrandar la escala de interpretación.

También, fue necesario excluir 881 objetos de aprendizaje de autoría de Colombia Aprende (468 de Primaria y 413 de Secundaria). La decisión se justificó en que estos recursos no se encuentran indexados; por ese motivo, no responden al botón de búsqueda y tampoco están ubicados en la estructura general del repositorio, sino que se ubican como un módulo independiente en

10. Es un espacio que organiza y publica contenidos digitales en diversos formatos.

11. En diseño web, las etiquetas o tags son palabras clave asignadas a un recurso para describirlo y ubicarlo fácilmente dentro de un repositorio. 
la sección central inferior de "Materiales educativos" (Figura 6). Su uso está supeditado a la exploración curiosa de algún usuario. En la misma línea, tampoco se tomó en cuenta el módulo "Materiales Educativos BIAE 2020", que contiene 675 textos escritos de autoría del Minedu (149 de Inicial, 409 de Primaria, 33 de Secundaria y 84 de EBA), dado que solo algunos de estos materiales son reconocidos por el botón de búsqueda y no están ubicados en el menú del repositorio. Sin tomar en cuenta los recursos excluidos, la figura 7 muestra que la mayor cantidad de recursos son videos (540) y en menor cantidad son juegos (5).

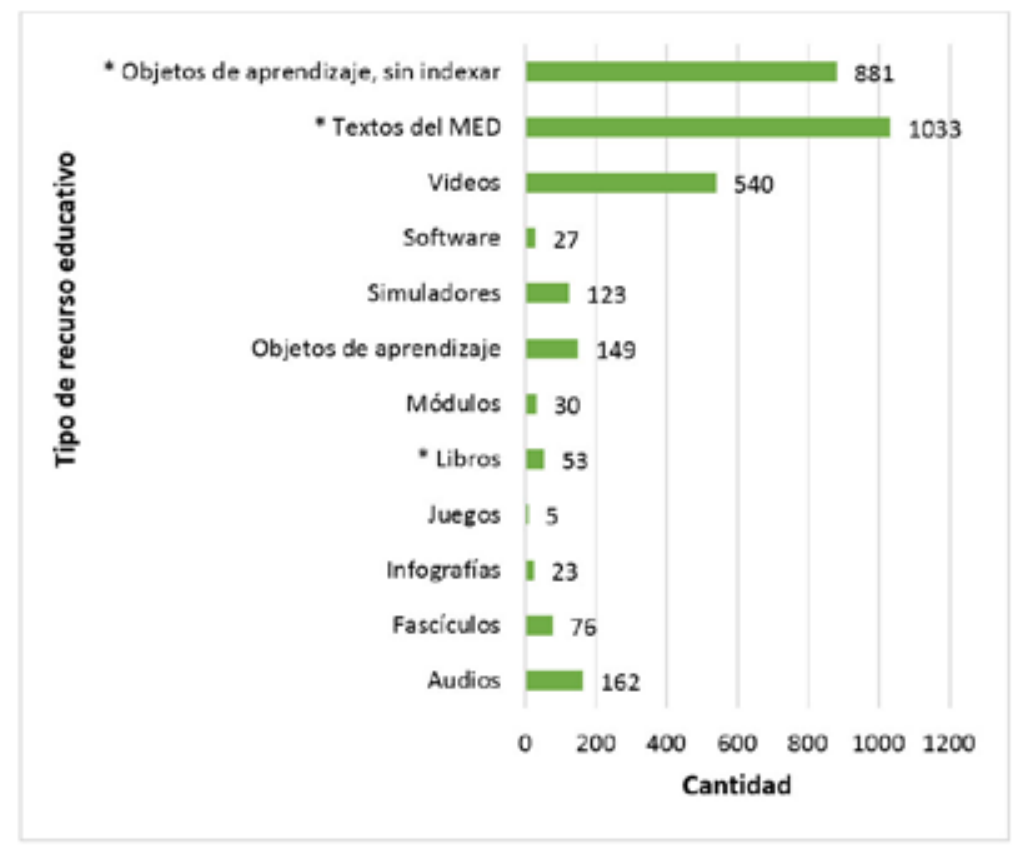

Figura 7. Cantidad de recursos educativos según tipo en el repositorio. Nota. Elaboración propia, con base en PerúEduca (2020).

Los tipos de recursos marcados con * son excluidos del análisis.

En sentido de lo anterior, los hallazgos encontrados en el proyecto de alfabetismo transmedia (Scolari, 2018) evidencian que los usuarios aprenden haciendo, a través de la práctica, la resolución de problemas, la imitación, el juego, la evaluación y la enseñanza. Al respecto, algunos recursos que se encontraron en menor cantidad en el portal fueron juegos y herramientas de autor (software), los cuales constituyen opciones útiles para el aprendizaje lúdico y la creación de materiales. Esto podría ayudar a pasar del actual modelo de aprendizaje enciclopédico y enciclopédico multimedial, que exhibe el portal, a un modelo de exploración y construcción que favorezca el desarrollo del pensamiento crítico. 


\section{Puntos de vista incorporados y usuarios implícitos}

Los recursos educativos incluidos en el portal provienen de diferentes autorías. En la figura 8, se observa la cantidad de recursos por autores, con las excepciones mencionadas antes:

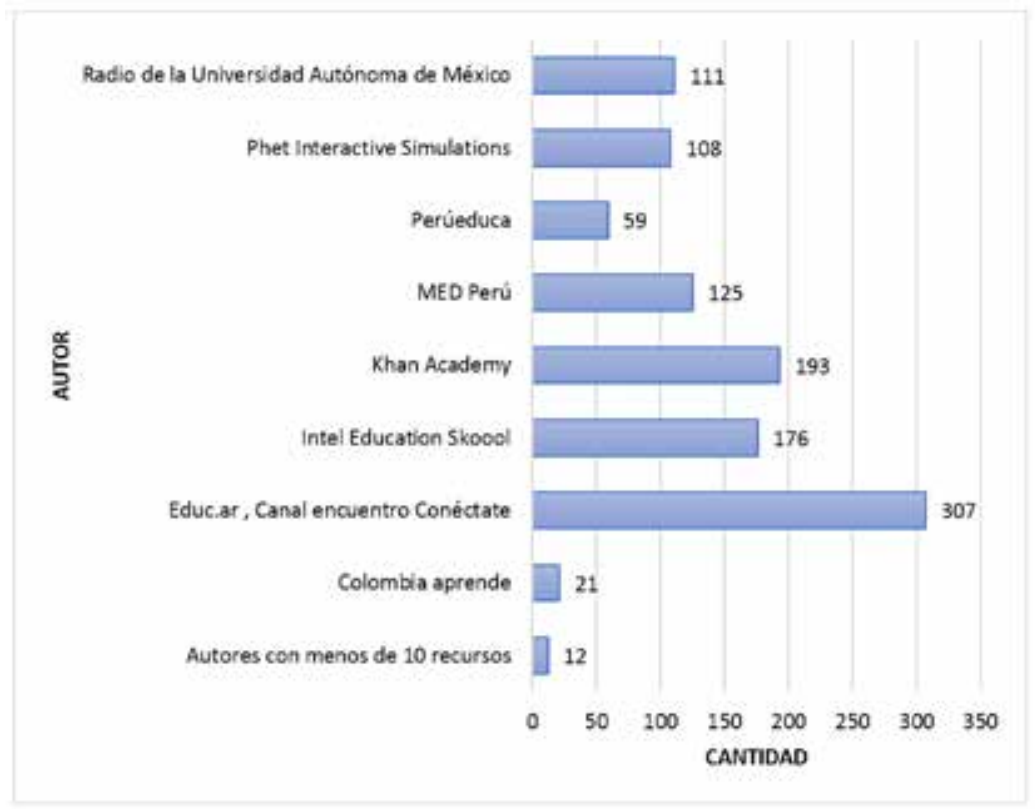

Figura 8. Cantidad de recursos educativos por autor

Nota. Elaboración propia, con base en PerúEduca (2020).

La figura 8 muestra que los recursos educativos del repositorio son producto de la colaboración con diversas fuentes cooperantes. Este trabajo de redes corresponde a dos principios básicos para el fomento de la interactividad: la alimentación del repositorio, y el mantenimiento de conexiones con nodos externos especializados para facilitar el aprendizaje continuo (Siemens, 2007). Además, se observa que existen pocos recursos digitales creados desde la propia dirección de tecnologías; de 1112 recursos, 59 son de autoría de PerúEduca, es decir, $5,31 \%$ del total.

A partir de esta data, se puede inferir que algunos países cuentan con instancias dedicadas a la construcción de materiales educativos digitales, como es el caso de Argentina (307 materiales), o Colombia (881 objetos de aprendizaje, que no han sido incluidos en el gráfico, dado que no se encuentran indexados).

Otro análisis realizado (esta vez, en el total de recursos, se incluyó el software), fue identificar cómo se distribuyen los recursos educativos por área curricular. La distribución de recursos se observa en la tabla 1: 
Tabla 1

Cantidad de recursos por área curricular y nivel, excepto libros, materiales BIAE y objetos de aprendizaje sin indexar

\begin{tabular}{|c|c|c|c|c|}
\hline \multirow[t]{2}{*}{ Áreas curriculares } & \multicolumn{3}{|c|}{ Nivel } & \multirow{2}{*}{$\begin{array}{l}\text { Total, por área } \\
\text { curricular }\end{array}$} \\
\hline & Inicial & Primaria & Secundaria & \\
\hline Arte & 0 & 1 & 5 & 6 \\
\hline Ciencia y tecnología & 72 & 99 & 540 & 711 \\
\hline Comunicación & 56 & 33 & 45 & 134 \\
\hline Educación física & 0 & 0 & 2 & 2 \\
\hline Educación para el trabajo & 0 & 0 & 36 & 36 \\
\hline Educación religiosa & 0 & 4 & 0 & 4 \\
\hline $\begin{array}{l}\text { Desarrollo personal, } \\
\text { ciudadanía y cívica }\end{array}$ & 0 & 0 & 11 & 11 \\
\hline Ciencias sociales & 0 & 0 & 31 & 31 \\
\hline Inglés & 0 & 0 & 10 & 10 \\
\hline Matemática & 5 & 16 & 31 & 52 \\
\hline Personal Social & 81 & 57 & 0 & 138 \\
\hline Total, por nivel & 214 & 210 & 711 & 1135 \\
\hline
\end{tabular}

Nota. Elaboración propia, con base en PerúEduca (2020).

$\mathrm{Al}$ respecto, se encontró que 711 recursos corresponden al área de Ciencia y Tecnología; esta cantidad equivale a $62,64 \%$ del total. Así también, se observa que, según modalidad, los niveles de Inicial (18,85 \%) y Primaria (18,5 \%) tienen menor cantidad de recursos en relación con el nivel Secundaria (Anexo 4).

De lo anterior, se colige que el usuario implícito del repositorio corresponderá preferentemente al nivel secundario, y dispondrá de materiales educativos referidos al área curricular de Ciencia y Tecnología.

\section{Análisis de las estrategias de priming}

El repositorio promueve el uso de materiales educativos que, en su mayoría, provienen de diferentes instituciones cooperantes. Este consumo colaborativo desafía las nociones tradicionales de la propiedad privada. Así, los usuarios que acceden al portal pueden descargar y utilizar el conocimiento creado por otros. Sin embargo, no se encuentra en el portal ninguna indicación sobre el uso ético de las licencias abiertas y cómo realizar las citas respectivas.

Finalmente, cabe señalar que la interfaz del repositorio no evidencia alguna estrategia periódica para la incorporación de nuevos recursos. Tampoco, 86 I se muestra algún sistema de comentarios o valoraciones, que permita hacer solicitudes, ajustes o mejoras. 


\section{Conclusiones}

Los portales educativos como espacios apartados de la publicidad, los blogs personales, las plataformas de venta, las fotografías de gatos y otros ruidos propios del internet tienen el potencial de constituirse como escenarios poderosos de aprendizaje. De ahí, radica su importancia para los actuales sistemas educativos, asentados a la fecha, ineludiblemente, en la modalidad de educación digital a distancia.

A pesar de lo anterior, la evidencia indica que PerúEduca se muestra más como un portal de noticias, que como una plataforma interactiva de aprendizaje. La interfaz de la página de Inicio y de la sección "Materiales educativos" cumplen mayormente tareas administrativas de entrega de información, en lugar de promover entornos de pensamiento crítico, alfabetización visual y construcción de aprendizajes. En este sentido, cabe recordar la necesidad urgente de implementar sitios web de uso pedagógico que sean abiertos, pues la riqueza del proceso educativo está en las conexiones, el conocimiento compartido y la inteligencia colectiva.

El portal contiene varios perfiles de usuario. De ellos, los usuarios focalizados son los docentes peruanos, a quiénes se dirigen la mayoría de las noticias y los cursos. En su mayoría, los cursos que se ofrecen son totalmente virtualizados; de esta forma, se promueve el trabajo autónomo. El usuario que cuenta con mayor cantidad de recursos se ubica en el nivel Secundaria, en el área curricular de Ciencia y Tecnología. Ninguno de los usuarios cuenta con la opción de agregar o cambiar contenidos. Los usuarios solo acceden al saber producido por otros, sin generar sus propias contribuciones. Al parecer, desde el portal, los usuarios están concebidos como destinatarios y no como actores del proceso.

La interactividad en el portal es unidireccional, es decir, planificada desde el usuario hacia el contenido del portal. No se promueven opciones de interacción entre usuarios; por lo tanto, las interfaces se presentan como espacios de circulación de información que va en un único sentido. Además, el portal se establece como una comunidad cerrada, aun para los peruanos que no cumplen con ciertos requisitos de acceso, tales como la autenticación a través del DNI o contar con todas las habilidades sensoriales. La falta del cumplimiento de principios de accesibilidad deja por fuera una parte de la población, que, dadas sus características, es especialmente vulnerable y necesita la mayor cantidad de recursos para acceder al aprendizaje. Por lo explicado, es muy recomendable que PerúEduca y otros portales públicos cumplan principios de accesibilidad, apertura e inclusión.

En el repositorio, se constató que existen muy pocos recursos de autoría nacional. Además, una tercera parte del total de recursos son reproducciones digitales de libros impresos, disponibles en formato PDF; cerca de la mitad de los recursos no son fácilmente utilizables, puesto que no responden al botón de búsqueda o no se encuentran indexados en los filtros del repositorio. Por 
otro lado, el repositorio sí permite usar/descargar recursos, aunque estos no pueden ser evaluados o comentados por los usuarios. También, se encontraron recursos educativos en lenguas originarias, aunque no cuentan con traducción al idioma castellano. Por último, el repositorio de PerúEduca es una muestra de la cooperación entre diversas instancias y podría ser utilizado para apuntalar aprendizajes complejos, pues incluye, en algunos casos, simuladores u otros desarrollos digitales que han sido diseñados para una modalidad de educación a distancia.

En el manejo visual, el texto lingüístico es predominante, y se presenta de forma aglomerada y reiterativa. Las fotos priorizan el mensaje del uso de la tecnología. Por su parte, los modos oracionales más utilizados transmiten indicaciones, cuya redacción asertiva o imperativa es atenuada con el uso de la segunda persona gramatical. La interfaz muestra reiteradamente íconos de redes sociales; sin embargo, el portal no brinda orientaciones sobre la participación que se espera del usuario en tales espacios o, incluso, en el mismo portal. En este punto, es difícil afirmar cuál es la instancia que debería orientar este tipo de aprendizajes, pues las competencias "se desenvuelve en los entornos virtuales generados por la TIC" y "gestiona su aprendizaje de manera autónoma" se encuentran incluidas en el programa curricular nacional (Minedu, 2016, p.29) en forma de competencias transversales, y, como tales, no cuentan con una carga horaria específica. Quizá, sea tiempo de hacer una revisión curricular en este sentido. 


\section{Referencias bibliográficas}

Adami, E. (2015). What's in a click? A social semiotic framework for the multimodal analysis of website interactivity. Visual Communication, 14(2), 133-153. https://doi.org/10.1177/1470357214565583

Area, M. (2017). La metamorfosis digital del material didáctico tras el paréntesis Gutenberg. RELATEC: Revista Latinoamericana de Tecnología Educativa, 16(2), 13-28.

Bal, M. (2017). Tiempos trastornados. Análisis, historias y políticas de la mirada. Akal. Bonett, D. C., Aguilar, A. S., Hidalgo, N., Gutiérrez, C., Mendoza, D., y Ruíz, R. (2020). 1. Acceso de los hogares a las Tecnologías de Información y Comunicación (TIC). Trimestre enero-febrero-marzo 2020 (Técnico 02 Junio 2020; Estadística TIC en los hogares, p. 55). Instituto Nacional de Estadística e Informática. https://www.inei.gob.pe/media/ MenuRecursivo/boletines/boletin_tics.pdf

Caballero-Cortés, L., Faba-Pérez, C., y de Moya-Anegón, F. (2009). Evaluación comparativa de la accesibilidad de los espacios web de las bibliotecas universitarias españolas y norteamericanas. Investigación bibliotecológica, 23(47), 45-66.

Calsamiglia, E., y Tusón, A. (2001). Las cosas del decir (2da.). Ariel.

Cobo, C. (2016). La innovación pendiente reflexiones (y provocaciones) sobre educación, tecnología y conocimiento. Colección Fundación Ceibal/ Debate.

Costa, F., Sánchez, A., Hidalgo, N., y Gutiérrez, C. (2018). Estadísticas de las Tecnologías de Información y Comunicación en los Hogares. Enerofebrero-Marzo 2018 (N. ${ }^{\circ}$ 2; p. 55). Instituto Nacional de Estadística. https://www.inei.gob.pe/media/MenuRecursivo/boletines/01-informetecnico-n02_tecnologias-de-informacion-ene-feb-mar2018.pdf

Flores, R., y Vásquez, L. (2013). Marketing Educativo- PerúEduca. https://www. academia.edu/5826074/Marketing_Educativo-_Per\%C3\%BAEduca

Gladic-Miralles, J., y Cautín-Epifani, V. (2016). Una mirada a los modelos multimodales de comprensión y aprendizaje a partir del texto. Literatura y lingüística, 34, 357-380. http://dx.doi.org/10.4067/S071658112016000200017

Keller, R. (2010). Sociology of Knowledge Approach to Discourse Analysis. A Research Programme for the Analysis of Social Relationships of Knowledge and Politics of Knowledge (B. Herzog y F. Hernández, Trads.). Forum Qualitative Sozialforschung / Forum: Qualitative Social Research, 11(3), Article 3. https://doi.org/10.17169/fqs-11.3.1494

Kress, G. (2010). Multimodality: A Social Semiotic Approach to Contemporary Communication. Routledge. 
Kress, G., y Van Leeuwen, T. (2001). Multimodal Discourse: The Modes and Media of Contemporary Communication. Arnold.

López-León, R. (2017). Fotografía, alfabetización visual y educación en diseño. Inventio, la génesis de la cultura universitaria en Morelos, 13(31), 65-69.

Martínez Rolán, X. (2019). Diseño de páginas web: Wordpress para todos los públicos. Editorial UOC. https://elibro.net/es/lc/sibdi/titulos/106387

Michelson, K., y Álvarez, J. (2016). Study Abroad: Tourism or education? A multimodal social semiotic analysis of institutional discourses of a promotional website. Discourse \& Communication, 10(3), 235-256. https:// doi.org/10.1177/1750481315623893

Ministerio de Educación. (2017). Programa Curricular de Educación Básica (1era. edición). Minedu. http://www.minedu.gob.pe/curriculo/pdf/ programa-curricular-educacion-secundaria.pdf

Olsen, G. (2003). Approaches to User Experience Design. https://boxesandarrows. com/files/banda/expanding_the_approaches_to_user_experience/ uxapproachesmodel.pdf

Parodi, G. (2010). Multisemiosis y lingüística de corpus: Artefactos (multi) semióticos en los textos de seis disciplinas en el corpus pucv-2010. RLA. Revista de lingüística teórica y aplicada, 48(2), 33-70. https://doi. org/10.4067/S0718-48832010000200003

Pauwels, L. (2012). A Multimodal Framework for Analyzing Websites as Cultural Expressions. Journal of Computer-Mediated Communication, 17(3), 247-265. https://doi.org/10.1111/j.1083-6101.2012.01572.x

Pérez-Montoro, M. (2010). Arquitectura de la información en entornos web. Gijón, Asturias, España: TREA.

PerúEduca. (2016, noviembre 11). Los primeros quince. https://www.youtube. $\mathrm{com} /$ watch? $\mathrm{v}=\mathrm{Tt} 2-\mathrm{L} 5 \mathrm{Dc}$-Es

PerúEduca. (2020). Sistema Digital para el Aprendizaje PerúEduca. perueduca. pe. https://cutt.ly/ep1UQLm

Portal PerúEduca. (2020, noviembre 7). PerúEduca 19 años [Imagen adjunta] [Publicación de estado]. Facebook. https://www.facebook.com/perueduca/ photos/a.10151065029490384/10164290375935384/

Red Latinoamericana de Portales Educativos. (2013). La nueva agenda de los portales educativos de América latina. Casos de Argentina. Chile y Perú. Organización de Estados Iberoamericanos. http://www2.congreso. gob.pe/sicr/cendocbib/con4_uibd.nsf/F65CA5089375780F05257E360 0782557/\$FILE/15-La-nueva-agenda-de-los-portales-educativos-deAm\%C3\%A9rica-latina-casos-de-Argentina-Chile-y-Per\%C3\%BA.pdf

Rovira, C., y Marcos, M.-C. (2013). Diseño de sitios web: Disciplinas, materias y esquemas integradores. Hipertext.net, $0(11)$. https://www.raco.cat/index. php/Hipertext/article/view/266846 
Scolari, C. (2004). Hacer clic: Hacia una sociosemiótica de las interacciones digitales. Editorial Gedisa.

Scolari, C. (2008). Hipermediaciones: Elementos para una Teoría de la Comunicación Digital Interactiva. Editorial GEDISA.

Scolari, C. (2018). Alfabetismo transmedia en la nueva ecología de los medios. Ars Media. http://www.codajic.org/sites/www.codajic.org/files/ Alfabetismo\%20Transmedia\%20.\%20Scolari_0.pdf

Serrano, E. (2009). Accesibilidad vs usabilidad web: Evaluación y correlación Accessibility vs. WEB Usability- Evaluation and Correlation. Investigación Bibliotecológica: Archivonomía, Bibliotecología e Información, 23(48), 61103.

Siemens, G. (2007). Conectivismo: Una Teoría del Aprendizaje para la Era Digital (D. Leal, Trad.). https://www.comenius.cl/recursos/virtual/minsal_v2/ Modulo_1/Recursos/Lectura/conectivismo_Siemens.pdf

Unidad de Estadística Educativa del Ministerio de Educación del Perú. (2020). Magnitudes de la Educación-ESCALE. Estadística de la calidad educativa. http://escale.minedu.gob.pe/magnitudes

Villa, N. H. (2008). Propuesta de alfabetización visual para estudiantes de educación básica apoyada en recursos hipermediales. Un aporte a la comprensión lectora. Revista Interamericana de Bibliotecología, 31(1), 207-225.

Yuan, K., Stecher, B. M., y Hamilton, L. S. (2015). Design of the Repository User Interface. En The Feasibility of Developing a Repository of Assessments of Hard-to-Measure Competencies (pp. 19-28). RAND Corporation. 
Anexo 1. Marco multimodal para analizar sitios web

1. Preservación de las primeras impresiones y reacciones

- Categorización de "mirar y sentir" a primera impresión

- Registro de reacciones afectivas

2. Inventario de características y temas destacados

- Inventario de las características y atributos actuales del sitio web

- Inventario de las principales categorías de contenido y temas.

- Categorizar y cuantificar características y temas

- Realizar un análisis “negativo": temas y características significativamente ausentes

3. Análisis en profundidad de contenido y características estilísticas de forma

3.1 Análisis intramodal (elementos: fijos/estáticos y móviles/dinámicos)

- Significantes verbales/escritos

- Significadores tipográficos

- Significadores representativos visuales

- Significantes sónicos

- Significantes de maquetación y diseño

3.2 Análisis de la interacción intermodal

- Relaciones de texto escrito/imagen y relaciones tipográficas en el texto escrito

- Relaciones de sonido/imagen

- Diseño general/interacción lingüística, visual y auditiva

3.3 Análisis "negativo" en profundidad

4. Punto(s) de vista o "voz" incorporados. público(s) implícito y propósitos

- Análisis del punto de vista de y personajes construidos.

- Análisis de audiencias intencionadas/implícitas

- Análisis de objetivos y propósitos integrados.

5. Análisis de la organización de la información y estrategias de priming espacial

- Opciones de estructura, navegación y limitaciones (organización dinámica)

- Análisis de estrategias de priming y herramientas de mantenimiento.

- Análisis de direccionamiento externo y/o características interactivas

- Análisis de hipervínculos externos.

6. Análisis del contexto, procedencia e inferencia

- Identificación de remitente (s) y fuentes

- La plataforma tecnológica, sus limitaciones/implicaciones.

- Atribución de la hibridación cultural 
Anexo 2. Análisis de los títulos de las noticias en la interfaz de Inicio

\begin{tabular}{|c|c|c|c|c|c|c|c|c|}
\hline \multirow{2}{*}{ 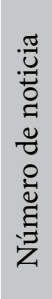 } & \multirow[b]{2}{*}{ Título de la noticia } & \multicolumn{4}{|c|}{$\begin{array}{c}\text { Modalidad de la } \\
\text { frase en el título de } \\
\text { la noticia }\end{array}$} & \multicolumn{3}{|c|}{$\begin{array}{l}\text { Persona } \\
\text { gramatical }\end{array}$} \\
\hline & & 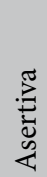 & 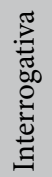 & 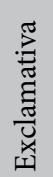 & 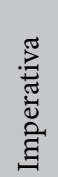 & 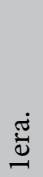 & : & 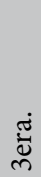 \\
\hline
\end{tabular}

1 Curso virtual “Cómo fortalecer el monitoreo y acompañamiento de la práctica pedagógica en el marco de Aprendo en $\begin{array}{lllllll}0 & 1 & 0 & 0 & 0 & 0 & 1\end{array}$ casa?"

2 Minedu inicia ciclo de inducción para capacitación a docentes sobre el uso y aprovechamiento pedagógico de las tabletas en 14 regiones del país

3 Minedu premiará a maestros y directivos por $\begin{array}{llllllll}\text { experiencias de aprendizaje y gestión escolar } & 1 & 0 & 0 & 0 & 0 & 0 & 1\end{array}$ a distancia

4 Invitamos a todos los docentes a preinscribirse en el curso "Rol ciudadano del $\begin{array}{lllllllll}1 & 0 & 0 & 0 & 1 & 0 & 0\end{array}$ docente frente al COVID-19"

5 Invitamos a todos los docentes a $\begin{array}{lllllllll}\text { preinscribirse en el curso "Rol docente como } & 1 & 0 & 0 & 0 & 1 & 0 & 0\end{array}$ mediador en la educación a distancia"

6 Sepa qué es el Registro de Datos del Personal de IIEE Privadas (REGIEP)

7 Curso de Emprendimiento en Educación Técnico Productiva, Superior Tecnológica y $\begin{array}{llllllll}1 & 0 & 0 & 0 & 0 & 0 & 1\end{array}$ Artística

8 Conoce más sobre el curso virtual de ofimática 2020

9150 años del nacimiento de María Montessori. Recordemos su legado

10 Participa de la encuesta sobre la forma de enseñar y aprender en este periodo de pandemia

11 Aprendo en casa llegará a zonas sin acceso a internet de la región Apurímac

12 ¿Cómo favorece la lactancia materna el desarrollo y el aprendizaje? Conoce la importancia de la lactancia materna 


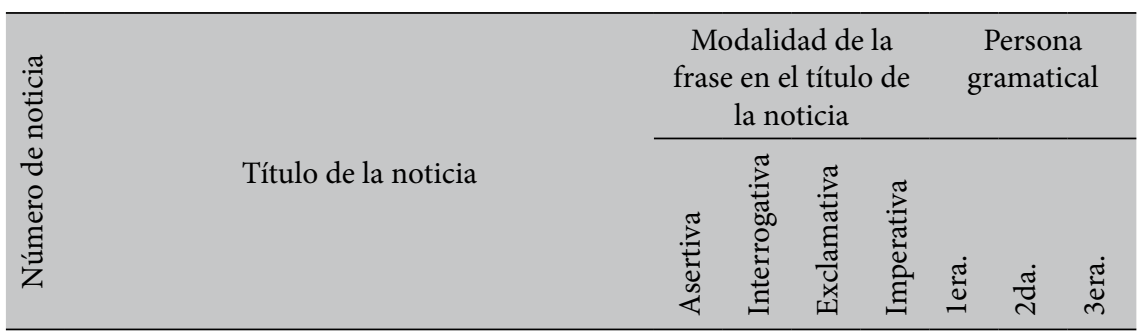

13 Cursos virtuales de "Escritura del wampis, shawi, nomatsigenga, kichwa (quechua amazónico) y quechua norteño". Si eres docente, preinscríbete.

14100,000 estudiantes de $5 .^{\circ}$ de Secundaria de EBR o $4 .^{\circ}$ grado del ciclo avanzado de EBA recibirán cursos de habilidades socioemocionales y TIC.

15 Accede a los 11000 contenidos en transformación digital que el Gobierno $\quad \begin{array}{lllllllll}0 & 0 & 0 & 1 & 0 & 1 & 0\end{array}$ peruano pone a disposición de la ciudadanía Totales

$\begin{array}{lllllll}7 & 2 & 0 & 6 & 3 & 6 & 6\end{array}$

1-10: ubicados en galería principal 11-13: ubicados en sidebar derecho 14 y 15: ubicados en sidebar inferior 
Anexo 3. Análisis de imagen en las noticias de la interfaz de Inicio

\begin{tabular}{|c|c|c|c|c|c|c|c|c|}
\hline \multirow[b]{2}{*}{ Nro. } & \multicolumn{6}{|c|}{ Imagen } & \multirow[b]{2}{*}{$\begin{array}{l}\text { Superposición } \\
\text { entre palabras }\end{array}$} & \multirow[b]{2}{*}{$\begin{array}{c}\text { Destinatario } \\
\text { (Docente } \\
\text { Familia } \\
\text { Estudiante) }\end{array}$} \\
\hline & $\begin{array}{l}\text { Fotografía/ } \\
\text { Ilustración }\end{array}$ & $\begin{array}{c}\text { Contiene } \\
\text { palabras } \\
\text { y gráficos }\end{array}$ & $\begin{array}{c}\text { Está } \\
\text { como } \\
\text { fondo de } \\
\text { palabras }\end{array}$ & $\begin{array}{c}\text { Las } \\
\text { palabras } \\
\text { repiten } \\
\text { información } \\
\text { del título }\end{array}$ & $\begin{array}{l}\text { : } \\
\text { है } \\
\text { : }\end{array}$ & $\frac{\dot{\Delta}}{\stackrel{\Xi}{\Sigma}}$ & & \\
\hline 1 & I & Sí & Sí & Sí & 1 & 0 & Sí & $\mathrm{D}$ \\
\hline 2 & $\mathrm{~F}$ & $\begin{array}{l}\text { Solo } \\
\text { gráfico }\end{array}$ & No & No & 0 & 2 & No & $\mathrm{D}$ \\
\hline 3 & $\mathrm{~F}$ & Sí & sí & No & 1 & 0 & Sí & $\mathrm{D}$ \\
\hline 4 & I & $\begin{array}{c}\text { Solo } \\
\text { palabras }\end{array}$ & Sí & Sí & 0 & 0 & Sí & $\mathrm{D}$ \\
\hline 5 & I & Sí & Sí & Sí & 1 & 0 & Sí & $\mathrm{D}$ \\
\hline 6 & $\mathrm{~F}$ & Sí & Sí & Sí & 0 & 1 & Sí & $\mathrm{D}$ \\
\hline 7 & I & Sí & Sí & Sí & 1 & 1 & Sí & $\mathrm{E}$ \\
\hline 8 & I & Sí & Sí & Sí & 0 & 1 & Sí & $\mathrm{D}$ \\
\hline 9 & $\mathrm{~F}$ & Sí & No & Sí & 3 & 3 & No & $\mathrm{D}$ \\
\hline 10 & $\mathrm{~F}$ & $\begin{array}{l}\text { Solo } \\
\text { gráfico }\end{array}$ & No & No & 1 & 0 & No & $\mathrm{D}$ \\
\hline 11 & $\mathrm{~F}$ & $\begin{array}{l}\text { Solo } \\
\text { gráfico }\end{array}$ & No & No & 2 & 0 & No & $\mathrm{D}$ \\
\hline 12 & I & Sí & No & Sí & 0 & 1 & Sí & $\mathrm{F}$ \\
\hline 13 & I & Sí & Sí & Sí & 2 & 2 & Sí & $\mathrm{D}$ \\
\hline 14 & $\mathrm{~F}$ & Sí & Sí & Sí & 1 & 1 & Sí & $\mathrm{F}$ \\
\hline 15 & I & Sí & Sí & Sí & 5 & 2 & Sí & $\mathrm{F}$ \\
\hline Totales & & & & & 18 & 14 & & \\
\hline
\end{tabular}

Son imágenes: 08 y fotografías: 07

La imagen contiene palabras y gráficos, 11: Sí; 03: solo palabras y 01: solo gráfico.

Está como fondo de palabras, 10: sí y 05: No.

Las palabras repiten información del título, 11: sí y 04: No.

Superposición entre palabras, 11: sí y 04: No.

Destinatario de la noticia, 11: docente, 03: familia y 01: estudiante. 
Anexo 4. Cantidad de materiales educativos, por área curricular, tipo de recurso y modalidad en el repositorio

\begin{tabular}{|c|c|c|c|c|c|c|c|c|c|c|c|c|}
\hline Inicial & 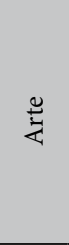 & 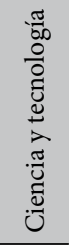 & 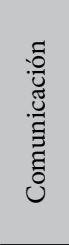 & 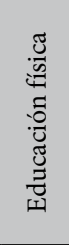 & 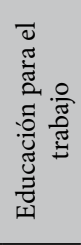 & 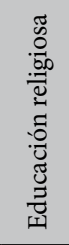 & 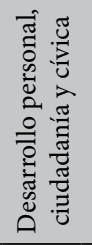 & 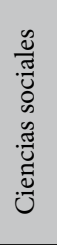 & 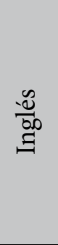 & 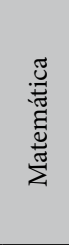 & 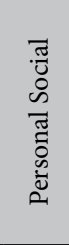 & 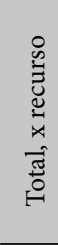 \\
\hline Audios & 0 & 0 & 4 & 0 & 0 & 0 & 0 & 0 & 0 & 0 & 0 & 4 \\
\hline Fascículos & 0 & 0 & 5 & 0 & 0 & 0 & 0 & 0 & 0 & 0 & 0 & 5 \\
\hline Infografías & 0 & 0 & 0 & 0 & 0 & 0 & 0 & 0 & 0 & 0 & 0 & 0 \\
\hline Juegos & 0 & 0 & 0 & 0 & 0 & 0 & 0 & 0 & 0 & 0 & 0 & 0 \\
\hline Libros & 0 & 0 & 0 & 0 & 0 & 0 & 0 & 0 & 0 & 0 & $\begin{array}{c}1 \\
\text { omt }\end{array}$ & 0 \\
\hline Módulos & 0 & 0 & 0 & 0 & 0 & 0 & 0 & 0 & 0 & 0 & 0 & 0 \\
\hline Objetos de aprendizaje & 0 & 0 & 0 & 0 & 0 & 0 & 0 & 0 & 0 & 0 & 0 & 0 \\
\hline Simuladores & 0 & 0 & 0 & 0 & 0 & 0 & 0 & 0 & 0 & 0 & 0 & 0 \\
\hline Software & 0 & 0 & 0 & 0 & 0 & 0 & 0 & 0 & 0 & 0 & 0 & 0 \\
\hline Textos MED & 0 & $\begin{array}{c}1 \\
\text { omt }\end{array}$ & $\begin{array}{l}180 \\
\text { omt }\end{array}$ & 0 & 0 & 0 & 0 & 0 & 0 & 0 & $\begin{array}{c}6 \\
\text { omt }\end{array}$ & 0 \\
\hline Videos & 0 & 72 & 47 & 0 & 0 & 0 & 0 & 0 & 0 & 5 & 81 & 205 \\
\hline Total, por área & 0 & 72 & 56 & 0 & 0 & 0 & 0 & 0 & 0 & 5 & 81 & 214 \\
\hline Primaria & 艺 & 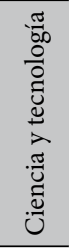 & 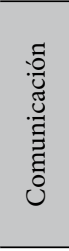 & 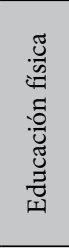 & 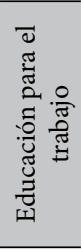 & 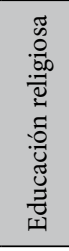 & 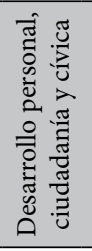 & 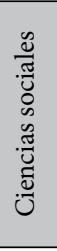 & $\frac{\mathscr{n}}{\not 0}$ & 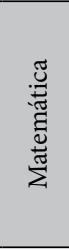 & 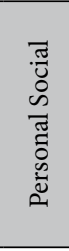 & 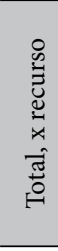 \\
\hline Audios & 0 & 61 & 16 & 0 & 0 & 0 & 0 & 0 & 0 & 0 & 0 & 77 \\
\hline Fascículos & 0 & 0 & 3 & 0 & 0 & 3 & 0 & 0 & 0 & 2 & 31 & 39 \\
\hline Infografías & 0 & 0 & 0 & 0 & 0 & 0 & 0 & 0 & 0 & 0 & 2 & 2 \\
\hline Juegos & 0 & 0 & 0 & 0 & 0 & 0 & 0 & 0 & 0 & 0 & 0 & 0 \\
\hline Libros & 0 & 0 & $\begin{array}{c}1 \\
\text { omt }\end{array}$ & 0 & 0 & 0 & 0 & 0 & 0 & $\begin{array}{c}1 \\
\text { omt }\end{array}$ & 0 & 0 \\
\hline Módulos & 0 & 6 & 0 & 0 & 0 & 1 & 0 & 0 & 0 & 0 & 0 & 7 \\
\hline Objetos de aprendizaje & 0 & 10 & 0 & 0 & 0 & 0 & 0 & 0 & 0 & 6 & 0 & 16 \\
\hline Simuladores & 0 & 0 & 0 & 0 & 0 & 0 & 0 & 0 & 0 & 0 & 0 & 0 \\
\hline Software & 1 & 2 & 2 & 0 & 0 & 0 & 0 & 0 & 0 & 1 & 0 & 6 \\
\hline Textos MED & $\begin{array}{c}2 \\
\text { omt }\end{array}$ & $\begin{array}{c}39 \\
\text { omt }\end{array}$ & $\begin{array}{l}408 \\
\text { omt }\end{array}$ & $\begin{array}{c}91 \\
\text { omt }\end{array}$ & 0 & $\begin{array}{c}1 \\
\text { omt }\end{array}$ & 0 & 0 & 0 & $\begin{array}{c}130 \\
\text { omt }\end{array}$ & $\begin{array}{c}96 \\
\text { omt }\end{array}$ & 0 \\
\hline Videos & & 20 & 12 & 0 & 0 & 0 & 0 & 0 & 0 & 7 & 24 & 63 \\
\hline Total, por área & 1 & 99 & 33 & 0 & 0 & 4 & 0 & 0 & 0 & 16 & 57 & 210 \\
\hline
\end{tabular}




\begin{tabular}{|c|c|c|c|c|c|c|c|c|c|c|c|c|}
\hline Secundaria & 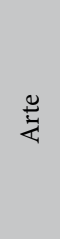 & 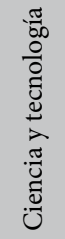 & 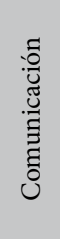 & 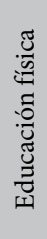 & 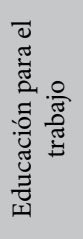 & 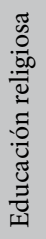 & 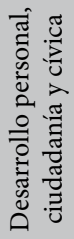 & 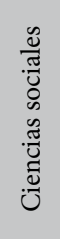 & $\frac{\mathscr{\Xi}}{\infty 00}$ & 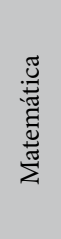 & 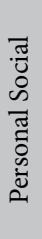 & 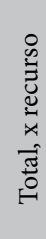 \\
\hline Audios & 0 & 50 & 31 & 0 & 0 & 0 & 0 & 0 & 0 & 0 & 0 & 81 \\
\hline Fascículos & 1 & 0 & 7 & 0 & 19 & 0 & 0 & 5 & 0 & 0 & 0 & 32 \\
\hline Infografías & 0 & 2 & 0 & 0 & 0 & 0 & 1 & 18 & 0 & 0 & 0 & 21 \\
\hline Juegos & 0 & 1 & 1 & 0 & 0 & 0 & 0 & 1 & 0 & 2 & 0 & 5 \\
\hline Libros & $\begin{array}{c}2 \\
\text { omt }\end{array}$ & $\begin{array}{c}8 \\
\text { omt }\end{array}$ & $\begin{array}{c}35 \\
\text { omt }\end{array}$ & 0 & 0 & 0 & 0 & $\begin{array}{c}2 \\
\text { omt }\end{array}$ & $\begin{array}{c}1 \\
\text { omt }\end{array}$ & $\begin{array}{c}2 \\
\text { omt }\end{array}$ & 0 & 0 \\
\hline Módulos & 2 & 17 & 0 & 0 & 0 & 0 & 0 & 0 & 0 & 4 & 0 & 23 \\
\hline Objetos de aprendizaje & & 115 & 0 & 0 & 0 & 0 & 0 & 0 & 0 & 18 & 0 & 133 \\
\hline Simuladores & 0 & 120 & 0 & 0 & 0 & 0 & 0 & 0 & 0 & 3 & 0 & 123 \\
\hline Software & 0 & 1 & 2 & 0 & 17 & 0 & 0 & 0 & 0 & 1 & 0 & 21 \\
\hline Textos MED & 0 & $\begin{array}{c}16 \\
\text { omt }\end{array}$ & $\begin{array}{c}35 \\
\text { omt }\end{array}$ & 0 & $\begin{array}{c}3 \\
\text { omt }\end{array}$ & 0 & $\begin{array}{c}21 \\
\text { omt }\end{array}$ & $\begin{array}{c}1 \\
\text { omt }\end{array}$ & 0 & $\begin{array}{c}3 \\
\text { omt }\end{array}$ & 0 & 0 \\
\hline Videos & 2 & 234 & 4 & 2 & 0 & 0 & 10 & 7 & 10 & 3 & 0 & 282 \\
\hline Total, por área & 5 & 540 & 45 & 2 & 36 & 0 & 11 & 31 & 10 & 31 & 0 & 711 \\
\hline
\end{tabular}

Nota: En las tablas “omt” significa omitido en el conteo. Es el caso de libros y textos MED. 